\title{
High union rates following surgical treatment of proximal fifth metatarsal stress fractures
}

\author{
Julian J. Hollander ${ }^{1,2,3} \cdot$ Quinten G. H. Rikken ${ }^{1,2,3} \cdot$ Jari Dahmen $^{1,2,3} \cdot$ Sjoerd A. S. Stufkens $\mathbf{S}^{1,2,3}$. \\ Gino M. M. J. Kerkhoffs ${ }^{1,2,3}$
}

Received: 6 December 2020 / Accepted: 3 February 2021 / Published online: 22 February 2021

(c) The Author(s) 2021

\begin{abstract}
Purpose The primary purpose of this study was to determine the union rate and time for surgical- and non-surgical treatment of stress fractures of the proximal fifth metatarsal (MT5). The secondary purpose was to assess the rate of adverse bone healing events (delayed union, non-union, and refractures) as well as the return to sports time and rate.

Methods A literature search of the EMBASE (Ovid), MEDLINE (PubMed), CINAHL, Web of Science and Google Scholar databases until March 2020 was conducted. Methodological quality was assessed by two independent reviewers using the methodological index for non-randomized studies (MINORS) criteria. The primary outcomes were the union time and rate. Secondary outcomes included the delayed union rate, non-union rate, refracture rate, and return to sport time and rate. A simplified pooling technique was used to analyse the different outcomes (i.e. union rate, time to union, adverse bone healing rates, return to sport rate, and return to sport time) per treatment modality. Additionally, $95 \%$ confidence intervals were calculated for the union rate, adverse bone healing rates, and the return to sport rate.

Results The literature search resulted in 2753 articles, of which thirteen studies were included. A total of 393 fractures, with a pooled mean follow-up of 52.5 months, were assessed. Overall, the methodological quality of the included articles was low. The pooled bone union rate was $87 \%$ (95\% CI 83-90\%) and 56\% (95\% CI 41-70\%) for surgically and non-surgically treated fractures, respectively. The pooled radiological union time was 13.1 weeks for surgical treatment and 20.9 weeks for non-surgical treatment. Surgical treatment resulted in a delayed union rate of 3\% (95\% CI 1-5\%), non-union rate of $4 \%$ (95\% CI 2-6\%) and refracture rate of $7 \%(95 \% \mathrm{CI} 4-10 \%)$. Non-surgical treatment resulted in a delayed union rate of $0 \%$ (95\% CI $0-8 \%$ ), a non-union rate of $33 \%$ (95\% CI 20-47\%) and a refracture rate of $12 \%$ (95\% CI 5-24\%), respectively. The return to sport rate (at any level) was $100 \%$ for both treatment modalities. Return to pre-injury level of sport time was 14.5 weeks (117 fractures) for surgical treatment and 9.9 weeks ( 6 fractures) for non-surgical treatment.

Conclusion Surgical treatment of stress fractures of the proximal fifth metatarsal results in a higher bone union rate and a shorter union time than non-surgical treatment. Additionally, surgical and non-surgical treatment both showed a high return to sport rate (at any level), albeit with limited clinical evidence for non-surgical treatment due to the underreporting of data. Level of evidence Level IV, systematic review.
\end{abstract}

Keywords Fifth metatarsal $\cdot$ Stress fracture $\cdot$ Conservative $\cdot$ Surgery $\cdot$ Non-surgical

Julian J. Hollander and Quinten G. H. Rikken equally contributed to this work and thus share first authorship.

Gino M. M. J. Kerkhoffs

g.m.kerkhoffs@amsterdamumc.nl

1 Department of Orthopaedic Surgery, Amsterdam Movement Sciences, Amsterdam UMC, Location AMC, University of Amsterdam, Meibergdreef 9, 1105 AZ Amsterdam, The Netherlands

\section{Abbreviations}

MT5 Fifth metatarsal

PRISMA The Preferred Reporting Items for Systematic Reviews and Meta-Analyses

2 Academic Center for Evidence Based Sports Medicine (ACES), Amsterdam UMC, Amsterdam, The Netherlands

3 Amsterdam Collaboration for Health and Safety in Sports (ACHSS), International Olympic Committee (IOC) Research Center, Amsterdam UMC, Amsterdam, The Netherlands 


$\begin{array}{ll}\text { MINORS } & \begin{array}{l}\text { Methodological Index for Non-Randomized } \\ \text { Studies }\end{array} \\ \text { BMI } & \text { Body mass index } \\ \text { RTS } & \text { Return to sport } \\ 95 \% \text { CI } & 95 \% \text { Confidence interval } \\ \text { IMS } & \text { Intramedullary screw } \\ \text { N/A } & \text { Not applicable }\end{array}$

\section{Introduction}

Stress fractures are partial or complete fractures that arise due to a repetitive load that is inferior to the stress required to break the bone within a single load [10]. A site of high incidence for stress fractures is the proximal fifth metatarsal (MT5), especially among (high-level) athletes [28]. Stress fractures of the proximal MT5 are problematic injuries as their inherent hypo-vascularity can lead to poor bone healing, which can result in a prolonged union time or even nonunion $[3,30]$. These complications can, in turn, affect the time to return to sports or work [8].

The treatment of proximal MT5 stress fractures can either be non-surgical or surgical [5, 9]. A preference for early surgical treatment of MT5 stress fractures exists in the literature as it seems to yield better bone healing outcomes and as well as a shorter bone union time in comparison to non-surgical treatment $[3,23]$. This suggests that surgical treatment is the preferred treatment method for MT5 stress fractures. To date, however, there are no existing studies that have specifically pooled the union outcomes for MT5 stress fractures that have been previously reported in the literature. Additionally, no overview is available on the return to sports time and rate after both surgical and non-surgical treatment. Consensus for the optimal treatment of MT5 stress fractures is, therefore, limited [12, 17, 27]. The union rate is an important clinical indicator for successful fracture treatment, and the findings of this study may aid surgeons in optimally treating patients with a MT5 stress fracture. The primary purpose of this study is to determine the union rate after both surgical and non-surgical treatment. The hypothesis of the present study is that surgical treatment will lead to a higher pooled union rate compared to non-surgical treatment. The secondary purpose is to determine the union time, the rate of adverse bone healing events (i.e. delayed- and non-union rates and refracture rate), and the return to sport time and rate.

\section{Materials and methods}

The study protocol was prospectively registered in an international prospective registry for systematic reviews, PROSPERO [4], with registration number: CRD42020178295.
The preferred reporting items for systematic reviews and meta-analyses (PRISMA) statement was used as a guideline for this study [16].

\section{Search strategy}

Studies from the first available record until March 2020 from EMBASE (Ovid), MEDLINE (PubMed), CINAHL, Web of Science and Google Scholar were searched. The full search strategy is available in the Appendix. Backwards citation chaining was applied to search for any additional eligible articles.

\section{Eligibility criteria and study selection}

All clinical studies that investigated either surgical or nonsurgical treatment of proximal MT5 stress fractures were included. Furthermore, studies written in English, French, German and Dutch were eligible for inclusion. There were no restrictions regarding patient age, demography or the date of publication. The exclusion criteria are shown in Table 1 . If the results of acute and stress fractures were combined in an eligible study, or if individual data for stress fractures was not presented, the corresponding author was contacted by e-mail to ask for the provision of additional data. Authors were also contacted in situations where it was unclear whether stress fractures were included or not. If no response was received, two reminder e-mails were sent. If the corresponding authors remained unresponsive, the article was excluded. Two independent reviewers (J.H. and Q.R.) performed the title and abstract screening, as well as the fulltext screening, using Rayyan [24]. In case of disagreement, an attempt was made to reach consensus. When no consensus was reached, the senior author (G.K.) was decisive.

\section{Methodological quality}

The methodological quality was evaluated by two independent reviewers (J.H. and Q.R.) using the Methodological Index for Non-Randomized Studies (MINORS) [29]. When no agreement was achieved after discussion, a third author (J.D.) was decisive.

Table 1 Exclusion criteria

Follow-up less than 3 months

Less than ten stress fractures reported

Reoperation as primary treatment following refracture or non-union

Review-, cadaver- and animal studies

Patient overlap 


\section{Data extraction}

Data extraction was independently performed by two reviewers (J.H. and Q.R.) using a standardized extraction form specifically designed for the present study and that was piloted before use. Authors cross-verified extracted data before analysis. Stress fractures were defined as a fracture with clinical or radiological signs of a chronic stress reaction to the proximal MT5 and included as determined by the respective authors $[6,9,25]$. Additionally, Torg type two and three fractures were also included as stress fractures in this review [31].

Data on study characteristics, patient characteristics, bone healing outcomes, and sport outcomes were collected. Study characteristics included author, title, level of evidence, year of publication, treatments reported, and follow-up duration. Patient data included gender, age, body mass index (BMI), activity level and fracture location according to Lawrence and Botte [14]. The bone healing outcomes that were extracted included the number of unions, time to radiological union, number of delayed- and non-unions, and the number of refractures. Sport outcomes included the rate of return to any/pre-injury level of sports and return to any/pre-injury level of sports time. If return to sport was not specified for pre-injury level or any level, it was considered as return to sports at any level. Additionally, all patient-reported and clinical outcome measures were extracted.

\section{Statistical analysis}

Descriptive variables were displayed as means with ranges for continuous variables, and absolute numbers and frequencies for categorical variables. Ranges of the reported pooled means and proportions include the lowest and highest mean values from the included studies. Time units were converted to either weeks or months, depending on the outcome variable. Due to the limited number of comparative studies, a formal meta-analysis was not carried out. Instead, a simplified pooling method was used, whereby pooled means and proportions were weighted by the number of fractures per study for each treatment modality (i.e. surgical or nonsurgical treatment).

The primary outcome-namely, the union rate-was defined as the proportion of unions per treatment modality, excluding refractures. The union rate was also pooled for specific treatments within both treatment modalities (e.g. casting for non-surgical treatment). Additionally, a subanalysis of the union rate for both treatment modalities per anatomical Lawrence and Botte zone was performed. For the secondary outcomes, the union time was pooled and weighted by the number of fractures per study. This was carried out for each treatment modality and their specific treatments. Furthermore, the rate of adverse bone healing events (i.e. the delayed union rate, non-union rate, and refracture rate) was calculated as the percentage of total fractures per treatment. To analyse the return to sport two different categories were used: return to sport at any level and return to sport at pre-injury level [1]. 95\% confidence intervals (95\% CI) were calculated within each pooled treatment modality and specific treatment group for the union rate, the rate of adverse bone healing events, and the return to sport rate using the Wilson score method (without continuity correction) [22]. All analyses were performed in STATA 15 (StataCorp LP, College Station, TX).

\section{Results}

\section{Article selection}

The literature search resulted in 2753 records, of which thirteen were included for final analysis after screening and contacting corresponding authors (Fig. 1). One prospective case series, nine retrospective case series and three retrospective comparative studies were included. A total of 393 stress fractures of the proximal MT5 were included in this review, with a mean age of 21.4 years (range: 19-28).

\section{Methodological quality}

The authors reached consensus on the MINORS score for each study. Non-comparative studies scored an average of 7.5 (range $4-12$ ) out of 16 points $[2,6,9,11,13,18,19$, $21,25,33]$. Comparative studies were scored at an average of 12.3 (range 12-13) out of 24 points $[5,15,26]$. The individual MINORS scores are available in the Appendix.

\section{Clinical outcomes}

\section{Surgical treatment}

Twelve studies reported outcomes of surgical treatment for a total of 350 fractures $[2,5,6,9,13,15,18,19,21,25$, $26,33]$. Four different surgical methods were reported, of which intramedullary screw (IMS) was most frequently used $(60 \%)$. The other techniques were tension band wiring (25\%), plantar plating (11\%), and medullary curettage $(0.1 \%)$. The study- and patient characteristics can be found in Table 2. The bone union rate for surgical treatment was $87 \%$ (95\% CI 83-90\%). Moreover, the pooled time to radiological union was 13.1 (range 7.5-42.6) weeks. The sub-analysis for the union rate of surgically treated zone 2 and 3 fractures-regardless of specific treatment-showed a union rate of $91 \%$ (95\% CI 82-95\%) and 91\% (95\% CI $82-96 \%$ ), respectively (Table 4). A full overview of the 


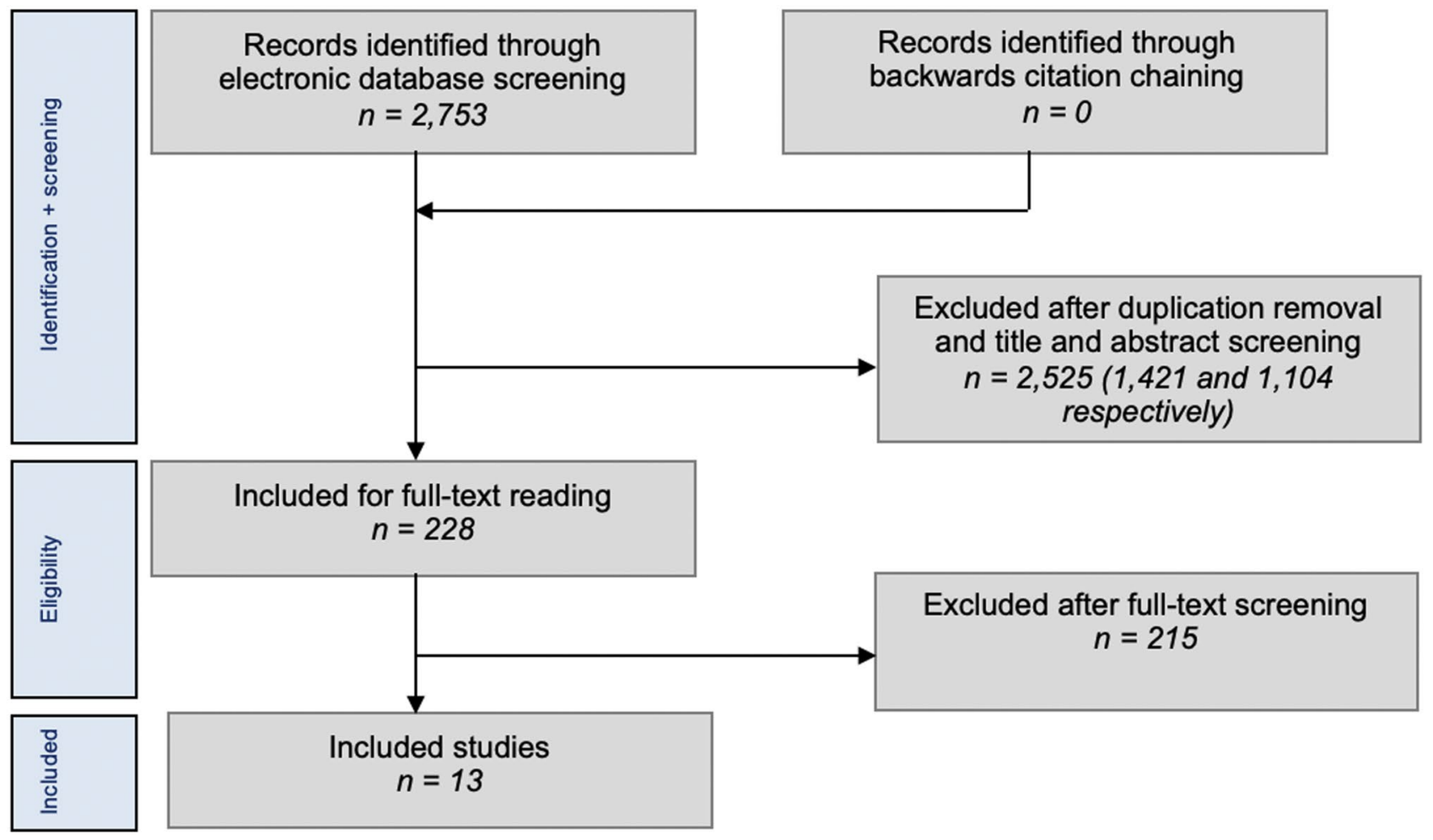

Fig. 1 PRISMA flowchart of study selection

secondary outcomes and sports outcomes per specific treatment is available in Tables 2 and 3.

\section{Non-surgical treatment}

Four studies-comprising a total of 43 fractures-reported outcomes for non-surgical treatment $[5,9,11,13]$. Patients were either treated with casting (33\%) or a combination of non-surgical treatments such as bandaging and weightbearing (53\%). The study and patient characteristics are depicted in Table 2. The pooled bone union rate for nonsurgical treatment was $56 \%$ (95\% CI $41-70 \%)$ and the radiological union time was 20.9 weeks. Furthermore, the sub-analysis of the union rate per anatomical zone for nonsurgical treatment showed a union rate of $65 \%$ (95\% CI $43-82 \%$ ) for zone 2 and $88 \%$ (95\% CI 53-98\%) for zone 3 fractures (Table 4). An overview of the union time and the rate of adverse bone healing events for non-surgical treatment is available in Table 2. Lastly, the pooled sports outcomes are reported in Table 3.

\section{Discussion}

The most important finding of this study is that surgical treatment of proximal MT5 stress fractures results in a short union time and a high union rate, with few adverse bone healing events (delayed union, non-union and refractures). The pooled union rate was found to be lower and the rate of adverse bone healing events higher for nonsurgically treated patients. Additionally, surgically treated patients were found to return to sports at any level sooner but at a similar rate as non-surgically treated patients, albeit with limited clinical evidence for non-surgical treatment.

\section{Fracture healing}

The present study shows that surgical treatment of proximal MT5 fractures results in lower rates of adverse bone healing events (i.e. delayed union, non-union and refracture rates) when compared to non-surgical treatment. A systematic review by Mallee et al. [17] concerning stress fractures in high-risk regions of the lower leg similarly found fewer adverse healing events and a shorter return 


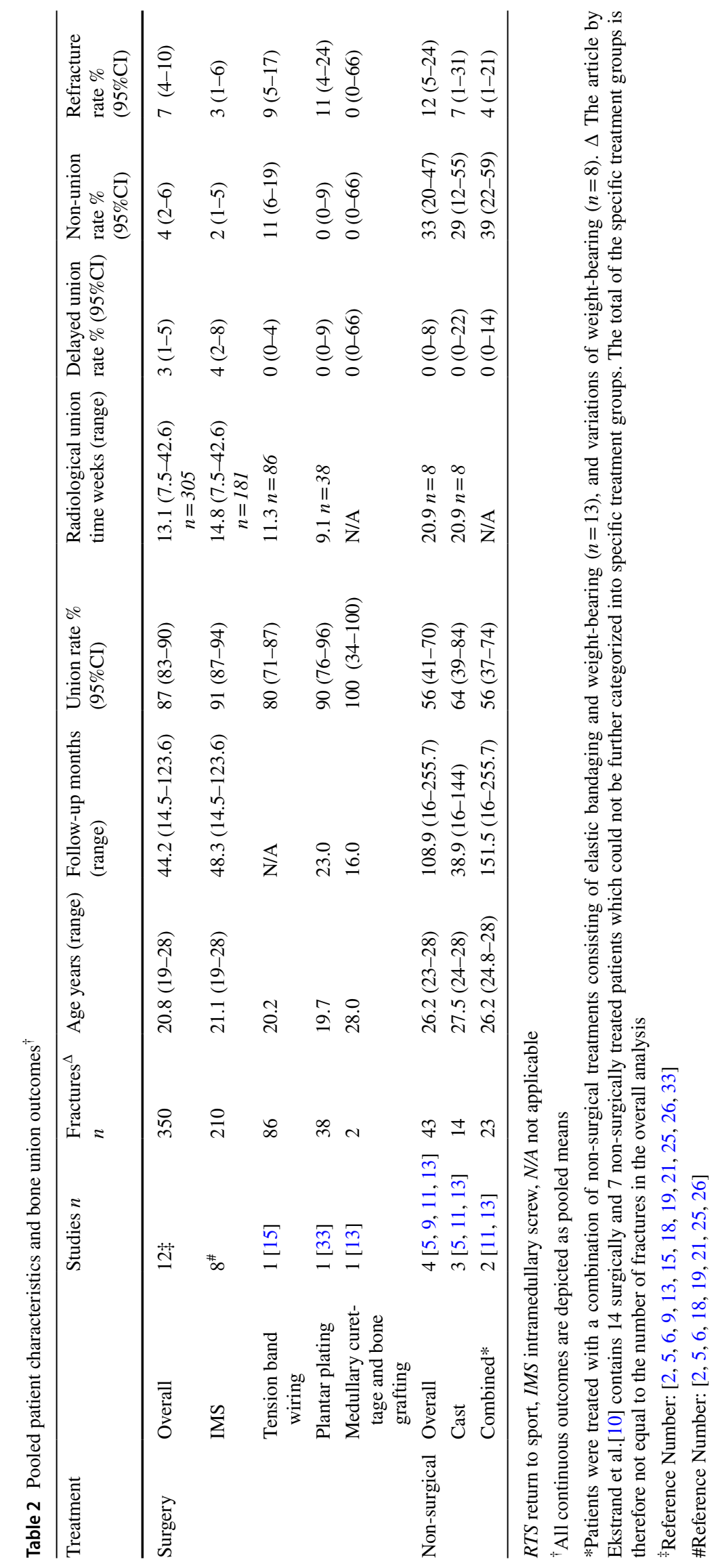


Table 3 Pooled sport outcomes ${ }^{\dagger}$

\begin{tabular}{|c|c|c|c|c|c|}
\hline Treatment & & $\begin{array}{l}\text { RTS rate at any } \\
\text { level \% (95\%CI) }\end{array}$ & $\begin{array}{l}\text { RTS time at any level } \\
\text { weeks (range) }\end{array}$ & $\begin{array}{l}\text { RTS rate at pre- } \\
\text { injury level } \\
\%(95 \% \mathrm{CI})\end{array}$ & $\begin{array}{l}\text { RTS time at pre- } \\
\text { injury level weeks } \\
\text { (range) }\end{array}$ \\
\hline \multirow[t]{4}{*}{ Surgery ${ }^{\#}$} & $\begin{array}{l}\text { Overall }[2,5,6,9,15,18,19,21 \text {, } \\
\quad 25,26,33]\end{array}$ & $\begin{array}{l}100 \\
(98-100) \\
n=231\end{array}$ & $\begin{array}{l}10.1 \\
(6.3-15.2) \\
n=253\end{array}$ & $\begin{array}{l}99 \\
(96-100) \\
n=171\end{array}$ & $\begin{array}{l}14.5 \\
(8.5-22.2) \\
n=117\end{array}$ \\
\hline & IMS $[2,5,6,18,19,21,25,26]$ & $\begin{array}{l}100 \\
(97-100) \\
n=107\end{array}$ & $\begin{array}{l}9.6 \\
(6.3-15.2) \\
n=201\end{array}$ & $\begin{array}{l}98 \\
(89-100) \\
n=47\end{array}$ & $\begin{array}{l}10.6 \\
(8.5-12) \\
n=65\end{array}$ \\
\hline & Tension band wiring [15] & $\begin{array}{l}100 \\
(96-100) \\
n=86\end{array}$ & N/A & $\begin{array}{l}100 \\
(96-100) \\
n=86\end{array}$ & N/A \\
\hline & Plantar plating [33] & $\begin{array}{l}97 \\
(87-100) \\
n=38\end{array}$ & $\begin{array}{l}11.6 \\
n=38\end{array}$ & $\begin{array}{l}97 \\
(87-100) \\
n=38\end{array}$ & $\begin{array}{l}22.2 \\
n=38\end{array}$ \\
\hline \multirow[t]{3}{*}{ Non-surgical } & Overall $[5,9,11]$ & $\begin{array}{l}100 \\
(78-100) \\
n=14\end{array}$ & $\begin{array}{l}19.3 \\
(9.9-26.3) \\
n=14\end{array}$ & N/A & $\begin{array}{l}9.9 \\
n=6\end{array}$ \\
\hline & Cast $[5,11]$ & $\begin{array}{l}100 \\
(21-100) \\
n=1\end{array}$ & $\begin{array}{l}26.3 \\
n=8\end{array}$ & N/A & N/A \\
\hline & Combined* [11] & $\begin{array}{l}100 \\
(77-100) \\
n=13\end{array}$ & N/A & N/A & N/A \\
\hline
\end{tabular}

$R T S$ return to sport, $N / A$ not applicable

${ }^{\dagger}$ All continuous outcomes are depicted as pooled means

*Patients were treated with variations of weight-bearing $(n=13)$

${ }^{\#}$ No sport outcomes for medullary curettage and bone grafting were reported

to sport time after surgical treatment of proximal MT5 stress fractures. The disparity in union rates between surgically and non-surgically treated fractures may be due to the prolonged fracture healing that is observed in stress fractures. Proximal MT5 fractures tend to show poor healing due to the limited blood supply and high load during sports with repetitive (micro)trauma [3, 28, 30]. Non-surgical treatment may, therefore, be unable to adequately stabilize these types of fractures that are frequently seen in physically active patient populations $[2,6,9,15,18$, $19,21,25,26,33]$. Surgical treatment may address this problem by providing an immediate stable fracture reduction which could allow for better callus formation and, therefore, superior healing [7]. As a result, patients are able to return to (full) weight-bearing and sporting activities at a faster rate. The trend towards increased surgical fixation for the management of these difficult fractures is clear in the literature. It must be stated, however, that the preference of surgical fixation over non-surgical treatment may lead to (publication) bias towards surgical treatment. Moreover, the results reported for surgically treated cases are often from (high-level) athletic patients, which may introduce selection bias [2, 6, 9, 15, 18, 19, 21, 25, 26, 33]. The available clinical results for non-surgical treatment are very limited in comparison with surgical interventions. Although surgery provides better union outcomes, nonsurgical therapy can still offer satisfying union outcomes and should always be considered in fracture treatment and patients with increased risk for surgical complications [5, 11]. It must also be pointed out that no formal statistical comparison between treatment modalities was made in the present study due to methodological considerations. Further research on both treatment modalities-non-surgical treatment in particular-is, therefore, necessary to provide more valid evidence for the superior treatment of MT5 stress fractures.

When interpreting the rate of delayed unions and nonunions, it should be noted that varying definitions were used in the studies included in this systematic review, or that the definitions were not reported $[7,10,12,14$, $16,20,22,34]$. A uniform definition is needed to enable improved analysis of the adverse bone healing events in further research. Additionally, varying imaging modalities were used to determine the time to union. This could affect the interpretation of this finding as the individual imaging modalities may have different sensitivities in the detection of bony union $[2,5,11,15,18,19,21,25,26$, 33]. However, radiographs were the most commonly used 


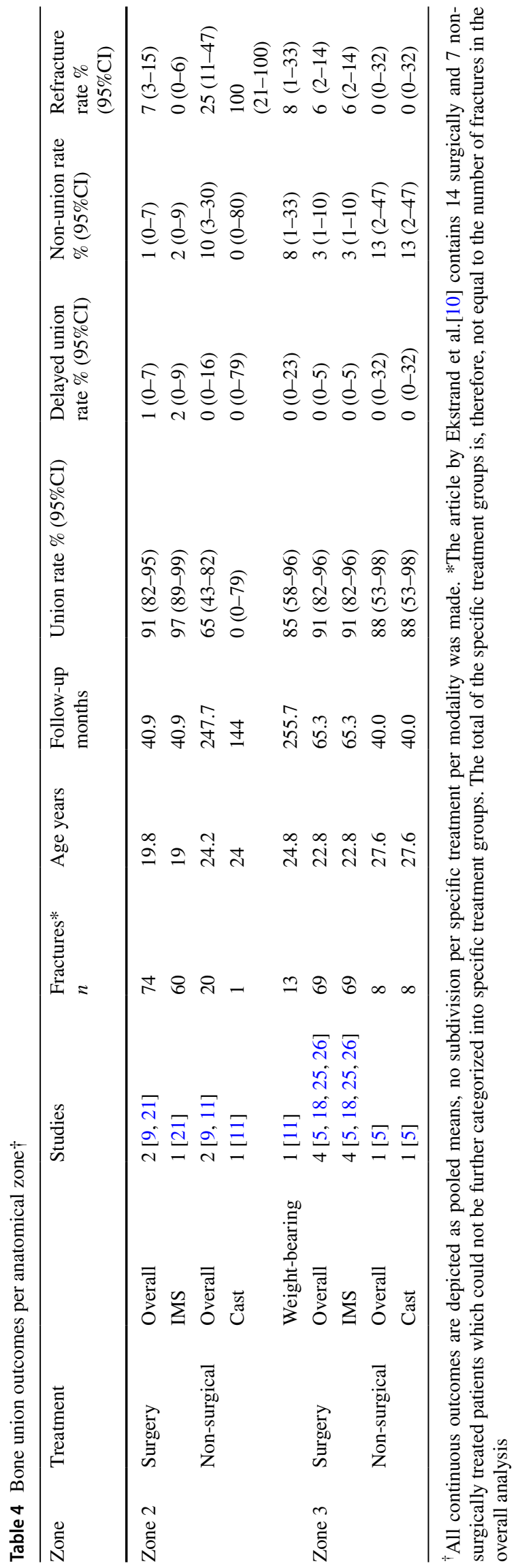

imaging modality in the included studies, thus limiting any possible bias.

\section{Surgical techniques}

Although it was not the aim of the present study to compare the different surgical techniques, it can be noted that the most commonly used technique was IMS fixation. Which type of surgical treatment leads to superior union rates and patient-reported outcomes remains to be elucidated. The present study found comparable union rates for fixation using an IMS, tension band wiring, and plating. The pooled refracture rate of IMS was the lowest when compared to the other techniques. Evidence for tension band wiring and plating was, however, limited. Except for one patient that was treated surgically after painful non-union that resulted from his/her primary non-surgical treatment [5], it was reported that all patients received primary surgical treatment without preoperative non-surgical therapy. Caution is warranted when interpreting these results due to the low number of studies.

\section{Fracture location}

The present study did not find a difference in union rates between Lawrence and Botte zone 2 and 3 fractures when treated surgically. Non-surgical treatment resulted in a lower union rate for zone 2 fractures compared to surgery. A previous systematic review on acute proximal MT5 fractures similarly found higher union rates for surgically treated patients [27]. These findings drive the hypothesis that Jones' (i.e. zone 2) fractures may be grouped into acute, sub-acute, and stress fractures as they are subject to increased stress forces and could, therefore, benefit from surgical fixation. Physicians should carefully consider the involvement of a stress phenomenon in zone 2 fractures and should take this into account when considering the optimal treatment.

\section{Return to sports}

In both the surgical and non-surgical treatment groups, almost all patients return to sport at any level. It was not possible to pool the return to sport rate at preinjury level for non-surgical treatment due to the underreporting of data. Surgical treatment was found to show a sooner return to sports at any level over non-surgical treatment, although data was limited. It must be acknowledged, however, that more research is needed to further investigate the return to sports after MT5 stress fracture treatment and what factors may contribute to a faster return to play. Lastly, it must be mentioned that preventative measures for MT5 stress fractures may spare patients the need for a surgical procedure that is accompanied by inherent risks $[2,33]$. 


\section{Methodological considerations}

The findings of the present study should be interpreted in the context of its design and limitations. The level of evidence of the included articles can be considered low, exemplified by the MINORS score. Except for one study, all included articles were of the retrospective design.

Limitations of this study include the small number of non-surgically treated patients and the fact that a formal statistical analysis was not able to be performed. This means that the present study did not make a direct statistical comparison between the outcomes of surgically and non-surgically treated patients. Caution is therefore warranted when interpreting the findings of this study as a variety of specific treatments were included with varying treatment indications. Additionally, the present study included articles with varying definitions of a stress fracture, which could have introduced a bias. However, a significant effort was made to contact authors in case it was not clear whether stress fractures were included or when additional data was needed.

\section{Clinical implications and future perspectives}

Using the currently available evidence, surgical treatment results in a high union rate for proximal MT5 stress fractures and may be considered as the optimal treatment. The present study highlights the healing complications seen after non-surgical treatment as well as the scarcity of data on the result of non-surgical treatment. The findings of the present study can aid physicians in determining the best treatment strategy for patients with a proximal MT5 stress fracture. Additionally, these findings can help physicians in the shared decision-making process with patients, and in the expectation management for return to sports and possible union complications after such a fracture.

Future research should focus on reporting prospectively gathered clinical and union outcomes for surgical and nonsurgical treatment modalities and should further investigate the factors associated with union complications and the failure of non-surgical treatment. The additional use of blood products such as bone marrow aspirate concentrate (BMAC) could enhance the fracture healing and return to sports and could be a promising adjuvant therapy $[20,26,32]$.

\section{Conclusion}

The union rate for surgically treated proximal MT5 stress fractures was found to be high with few adverse bone healing events (delayed union, non-union and refractures), whilst non-surgical treatment resulted in a lower union rate. The pooled union time was found to be longer in non-surgically treated patients. Additionally, surgical and non-surgical treatment both showed a high return to sport rate (at any level), albeit with limited clinical evidence for non-surgical treatment due to the underreporting of data.

Acknowledgements The authors would like to thank F. van EttenJamaludin of the AMC Medical Library for her help with the literature search and J. van Oosterhout for her assistance with drafting the manuscript.

Author contributions JH, QR and JD have made substantial contributions to conception and design, acquisition of data, analysis and interpretation of data, and have been involved in drafting the manuscript. SAS and GK have been involved in revising the manuscript, critically for important intellectual content, and have given final approval of the version to be published.

Funding No funding was received for this study.

\section{Compliance with ethical standards}

Conflict of interest All authors report no conflict of interest.

Ethical Approval Not applicable to this study.

Open Access This article is licensed under a Creative Commons Attribution 4.0 International License, which permits use, sharing, adaptation, distribution and reproduction in any medium or format, as long as you give appropriate credit to the original author(s) and the source, provide a link to the Creative Commons licence, and indicate if changes were made. The images or other third party material in this article are included in the article's Creative Commons licence, unless indicated otherwise in a credit line to the material. If material is not included in the article's Creative Commons licence and your intended use is not permitted by statutory regulation or exceeds the permitted use, you will need to obtain permission directly from the copyright holder. To view a copy of this licence, visit http://creativecommons.org/licenses/by/4.0/.

\section{References}

1. Ardern CL, Glasgow P, Schneiders A, Witvrouw E, Clarsen B, Cools A et al (2016) 2016 Consensus statement on return to sport from the First World Congress in Sports Physical Therapy, Bern. Br J Sports Med 50:853-864

2. Baumfeld T, Fernandes Rezende R, Nery C, Batista JP, Baumfeld D (2020) Fifth metatarsal fractures in professional soccer players: case series. Foot Ankle Spec. https://doi.org/10.1177/1938640020 9112231938640020911223

3. Cheung CN, Lui TH (2016) Proximal fifth metatarsal fractures: anatomy, classification treatment and complications. Arch Trauma Res 5:e33298

4. Chien PF, Khan KS, Siassakos D (2012) Registration of systematic reviews: PROSPERO. BJOG 119:903-905

5. Chuckpaiwong B, Queen RM, Easley ME, Nunley JA (2008) Distinguishing Jones and proximal diaphyseal fractures of the fifth metatarsal. Clin Orthop Relat Res 466:1966-1970

6. DeLee JC, Evans JP, Julian J (1983) Stress fracture of the fifth metatarsal. Am J Sports Med 11:349-353

7. Duplantier NL, Mitchell RJ, Zambrano S, Stone AC, Delgado DA, Lambert BS et al (2018) A biomechanical comparison of fifth metatarsal Jones fracture fixation methods. Am J Sports Med 46:1220-1227 
8. Ekstrand J, Torstveit MK (2010) Stress fractures in elite male football players. Scand J Med Sci Sports 22:341-346

9. Ekstrand J, van Dijk CN (2013) Fifth metatarsal fractures among male professional footballers: a potential career-ending disease. Br J Sports Med 47:754-758

10. Fredericson M, Jennings F, Beaulieu C, Matheson GO (2006) Stress fractures in athletes. Top Magn Reson Imaging 17:309-325

11. Josefsson PO, Karlsson M, Redlund-Johnell I, Wendeberg B (1994) Closed treatment of Jones fracture. Good results in 40 cases after 11-26 years. Acta Orthop Scand 65:545-547

12. Kerkhoffs GM, Versteegh VE, Sierevelt IN, Kloen P, van Dijk CN (2012) Treatment of proximal metatarsal V fractures in athletes and non-athletes. Br J Sports Med 46:644-648

13. Khan W, Agarwal M, Warren-Smith C (2005) Management of fractures of the base of the fifth metatarsal distal to the tuberosity. The Foot 15:141-145

14. Lawrence SJ, Botte MJ (1993) Jones' fractures and related fractures of the proximal fifth metatarsal. Foot Ankle 14:358-365

15. Lee KT, Park YU, Jegal H, Park JW, Choi JP, Kim JS (2013) Prognostic classification of fifth metatarsal stress fracture using plantar gap. Foot Ankle Int 34:691-696

16. Liberati A, Altman DG, Tetzlaff J, Mulrow C, Gotzsche PC, Ioannidis JP et al (2009) The PRISMA statement for reporting systematic reviews and meta-analyses of studies that evaluate healthcare interventions: explanation and elaboration. BMJ 339:b2700

17. Mallee WH, Weel H, van Dijk CN, van Tulder MW, Kerkhoffs GM, Lin CW (2015) Surgical versus conservative treatment for high-risk stress fractures of the lower leg (anterior tibial cortex, navicular and fifth metatarsal base): a systematic review. Br J Sports Med 49:370-376

18. Massada MM, Pereira MA, de Sousa RJ, Costa PG, Massada JL (2012) Intramedullary screw fixation of proximal fifth metatarsal fractures in athletes. Acta Ortop Bras 20:262-265

19. Miller D, Marsland D, Jones M, Calder J (2019) Early return to playing professional football following fixation of 5th metatarsal stress fractures may lead to delayed union but does not increase the risk of long-term non-union. Knee Surg Sports Traumatol Arthrosc 27:2796-2801

20. Murawski CD, Kennedy JG (2011) Percutaneous internal fixation of proximal fifth metatarsal jones fractures (Zones II and III) with Charlotte Carolina screw and bone marrow aspirate concentrate: an outcome study in athletes. Am J Sports Med 39:1295-1301

21. Nagao M, Saita Y, Kameda S, Seto H, Sadatsuki R, Takazawa Y et al (2012) Headless compression screw fixation of Jones fractures: an outcomes study in Japanese athletes. Am J Sports Med 40:2578-2582

22. Newcombe RG (1998) Two-sided confidence intervals for the single proportion: comparison of seven methods. Stat Med $17: 857-872$
23. Nunley JA (2001) Fractures of the base of the fifth metatarsal: the Jones fracture. Orthop Clin North Am 32:171-180

24. Ouzzani M, Hammady H, Fedorowicz Z, Elmagarmid A (2016) Rayyan - a web and mobile app for systematic reviews. System Rev 5:210

25. Pecina M, Bojanic I, Smoljanovic T, Ivkovic A, Mirkovic M, Jelic M (2011) Surgical treatment of diaphyseal stress fractures of the fifth metatarsal in competitive athletes: long-term follow-up and computerized pedobarographic analysis. J Am Podiatr Med Assoc 101:517-522

26. Popovic N, Jalali A, Georis P, Gillet P (2005) Proximal fifth metatarsal diaphyseal stress fracture in football players. Foot Ankle Surg 11:135-141

27. Rikken QGH, Dahmen J, Hagemeijer NC, Sierevelt IN, Kerkhoffs GMMJ, DiGiovanni CW (2020) Adequate union rates for the treatment of acute proximal fifth metatarsal fractures. Knee Surg Sports Traumatol Arthroscopy. https://doi.org/10.1007/s0016 7-020-06072-8

28. Shindle MK, Endo Y, Warren RF, Lane JM, Helfet DL, Schwartz EN et al (2012) Stress fractures about the tibia, foot, and ankle. J Am Acad Orthop Surg 20:167-176

29. Slim K, Nini E, Forestier D, Kwiatkowski F, Panis Y, Chipponi J (2003) Methodological index for non-randomized studies (minors): development and validation of a new instrument. ANZ J Surg 73:712-716

30. Smith JW, Arnoczky SP, Hersh A (1992) The intraosseous blood supply of the fifth metatarsal: implications for proximal fracture healing. Foot Ankle 13:143-152

31. Torg JS, Balduini FC, Zelko RR, Pavlov H, Peff TC, Das M (1984) Fractures of the base of the fifth metatarsal distal to the tuberosity. Classification and guidelines for non-surgical and surgical management. JBJS 66:209-214

32. Weel H, Mallee WH, van Dijk CN, Blankevoort L, Goedegebuure S, Goslings JC et al (2015) The effect of concentrated bone marrow aspirate in operative treatment of fifth metatarsal stress fractures; a double-blind randomized controlled trial. BMC Musculoskeletal Disorders 16:211

33. Young KW, Kim JS, Lee HS, Jegal H, Park YU, Lee KT (2020) Operative results of plantar plating for fifth metatarsal stress fracture. Foot Ankle Int. https://doi.org/10.1177/107110071989527 31071100719895273

Publisher's Note Springer Nature remains neutral with regard to jurisdictional claims in published maps and institutional affiliations. 